\title{
Investigation on the improvement of car air conditioning system performance using an ejector
}

\author{
Enang Suma Arifianto ${ }^{1}$, Ega Taqwali Berman ${ }^{1, *}$, and Mutaufiq Mutaufiq ${ }^{1}$ \\ ${ }^{1}$ Universitas Pendidikan Indonesia, Departement of Mechanical Engineering Education, Bandung, Indonesia
}

\begin{abstract}
The purpose of this research is to know the improvement of car air conditioner system performance using an ejector. The study was conducted on a car engine with power 100 PS (74 kW) (a) $5000 \mathrm{rpm}$. The test procedure is carried out under two conditions: the normal refrigeration cycle mode and the refrigeration cycle mode with the ejector. The working fluid used in the refrigeration cycle is R-134a. Performance data was measured on engine revolutions ranging from 1500 - $3000 \mathrm{rpm}$. Finally, the results showed that ejector usage on $\mathrm{AC}$ system generates an increase in the refrigeration effect and coefficient of performance (COP) of $25 \%$ and $22 \%$, respectively. This has implications to better cooling capacity and compressor work that is lighter.
\end{abstract}

\section{Introduction}

Nowadays every modern vehicle is equipped with air conditioning system (AC). The existence of air conditioning has become a primary human need in supporting its daily activities. AC can create comfortable conditions inside the cabin during the summer and can prevent the formation of fog in the front window during the rainy season [1].

In general, the type of air conditioner used in a vehicle is a vapor compression cycle with HFC 134a as its refrigerant. the vapor compression cycle is widely used in vehicles because it has significant efficiency, low refrigerant volume and the weight of circulated refrigerant is small [2]. The main components of the vapor compression cycle are compressors, two heat exchangers, and expansion valves (TXV). Traditionally, the $\mathrm{AC}$ system is driven by the engine through a belt and the ratio of engine speed and compressor is fixed value. Therefore, the on/off compressor arrangement and the magnetic clutch on/off can be performed by the AC temperature switch [3]. With the global energy crisis, the high energy consumption generated by vehicles should be reduced immediately. Specifically, car air conditioning consumes $12 \%-17 \%$ energy of total car energy and a way to save energy has become an important issue in designing $\mathrm{AC}$ system $[4,5]$.

One way that can be done to reduce the car engine load is by increasing the performance of the vapor compression cycle as shown by the increasing value of the refrigeration effect. The greater the value of the refrigeration effect then the amount of heat that can be absorbed by the refrigerant from the cabin space is greater [6].

Some researchers propose the use of ejector as an expander on AC systems. Theoretically, the expansion process by TXV occurs in isenthalpic (enthalpy constant). The isenthalpic process results in a reduced cooling capacity resulting in an energy loss $[7,8]$. To reduce this energy loss, the isentropic process is required in the expansion process. An ejector can be used to produce an isentropic condition during the throttling process [9].

Experiments using ejectors have been conducted by researchers to improve the performance of vapor compression refrigeration cycles. The research team has performed computational analysis on R-134a cooling machine using ejector [10]. The result shows that the increase of refrigeration cycle performance is $10,1 \%$ $22,34 \%$ compared to conventional refrigeration cycle (without ejector). In another study, experiments and numerical analyzes have been performed to observe the performance of a split AC vapor compression refrigeration cycle that installed ejector devices [11]. Experimental results show that the modified refrigeration cycle using ejector increases COP by $4.17 \%-13.78 \%$ at ambient temperature of $30 \mathrm{C}-40 \mathrm{C}$.

The purpose of this research is to improve the performance of car air conditioning system by using ejector as expander. The results are expected to reduce the engine load and fuel consumption of the car when the AC system works.

\section{Materials and experimental method}

Figure 1 shows the ejector installation layout on the car air conditioning system used in the experiment. Car air conditioning system consists of main components and secondary components. The main components consist of compressors (sanden SD-507), air-cooled condensers, thermostatic expansion valves (TXV), and finned evaporators. The secondary component consists of

\footnotetext{
* Corresponding author: egatb@upi.edu
} 
separator, filter dryer, sight glass, five hand valve units, and ejector to reduce energy loss during expansion process. All components are installed on an experimental device with engine specifications of 100 PS (74 kW) @ $5000 \mathrm{rpm}$. Installation connection between components using copper pipe and flexible pipe size 1/4 ", 3/8", 1/2 ", and $5 / 8$ " The refrigerant used as working fluid is $\mathrm{R} 134 \mathrm{a}$.

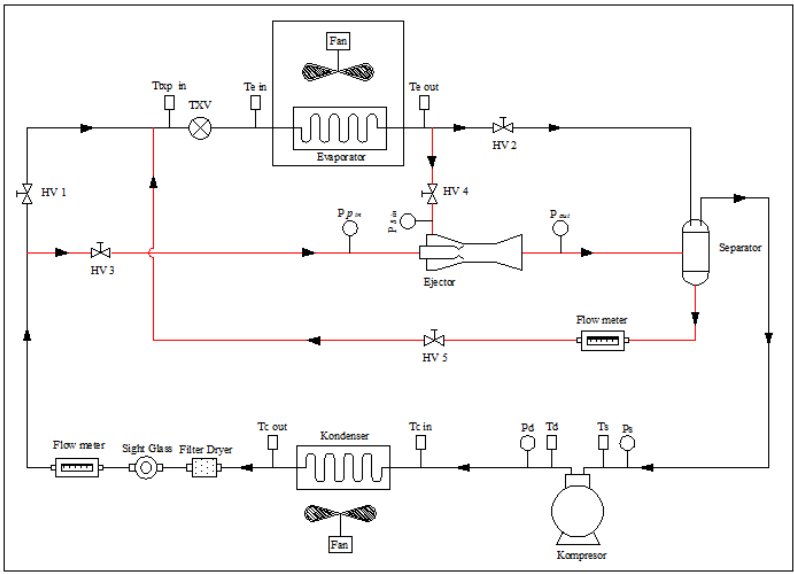

Fig. 1. Layout of the car air conditioning system with ejector.

The testing procedure begins with setting up the measuring instrument. Thermometer (Lutron TM-903A, Taiwan) and pressure gauge (Value, China) are installed in the car air conditioning piping system to measure the temperature and pressure of the refrigerant. The thermometer is installed in the inlet/outlet of the main component of AC and the pressure gauge is installed in the inlet/outlet of the compressor and ejector. Furthermore the car air conditioning system is operated on two conditions. The first condition operates normally (without ejector). The second, air conditioning systems operate by using ejector. To operate normal air conditioning systems hand valve (HV) $3, \mathrm{HV} 4$, and $\mathrm{HV}$ 5 are closed. Then to operate the car air conditioner using ejector, HV 1 and HV 2 are closed.

Before the AC system is operated, flushing is done first to clean the dirt present in the piping due to pipe connection by brazing process. Next do a leak test by entering the nitrogen into the pipeline with a pressure of 40 Psi to 100 Psi. Next the AC system is vacuumed for 25 minutes. Then refill 134A into AC system until suction pressure about 20-30 Psi. After that, the AC system is left for 20 minutes to reach steady condition. Finally, temperature and pressure data are recorded. Temperature and pressure data are taken at engine speeds between $1500 \mathrm{rpm}$ to $3000 \mathrm{rpm}$. Furthermore, temperature and pressure data is used to determine the performance improvement of car air conditioners that have been installed ejector.

\section{Results and discussion}

The results were obtained from the performance testing of the air conditioning system in two operating conditions: normal and with ejector. Tests were carried out at an ambient temperature of $28 \mathrm{C}$ and a time interval of data recording every three minutes starting from 21 st minute.

\subsection{Refrigeration effect}

Figure 2 shows the value of the refrigeration effect of the AC system under normal conditions testing. The test is done on three variations of rpm that is $1500 \mathrm{rpm}, 2000$ rpm, and $3000 \mathrm{rpm}$.

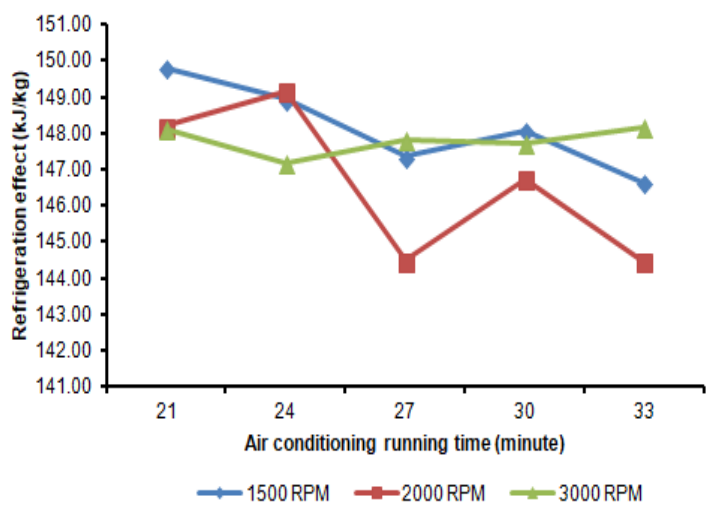

Fig. 2. Value of refrigeration effect based on time interval on normal condition testing.

In general, the resulting refrigeration effect at the end of the data retrieval at $3000 \mathrm{rpm}$ is higher than at the other two rpm. At the beginning of the test, the effect of refrigeration obtained was $148.13 \mathrm{~kJ} / \mathrm{kg}$. Then the value fluctuates up to $148.17 \mathrm{~kJ} / \mathrm{kg}$ in the final minutes. On the other hand, in the early minutes the refrigeration effect at $1500 \mathrm{rpm}$ and $2000 \mathrm{rpm}$ is greater, respectively 149.82 $\mathrm{kJ} / \mathrm{kg}$ and $148.20 \mathrm{~kJ} / \mathrm{kg}$. Furthermore, the value of the refrigeration effect of both $\mathrm{rpm}$ has decreased significantly in the final minutes of data collection that is $146.64 \mathrm{~kJ} / \mathrm{kg}$ and $144.47 \mathrm{~kJ} \mathrm{~kg}$. Different results were obtained under other test conditions of the AC system.

Figure 3 shows the refrigeration effect of the $\mathrm{AC}$ system on the test using ejector.

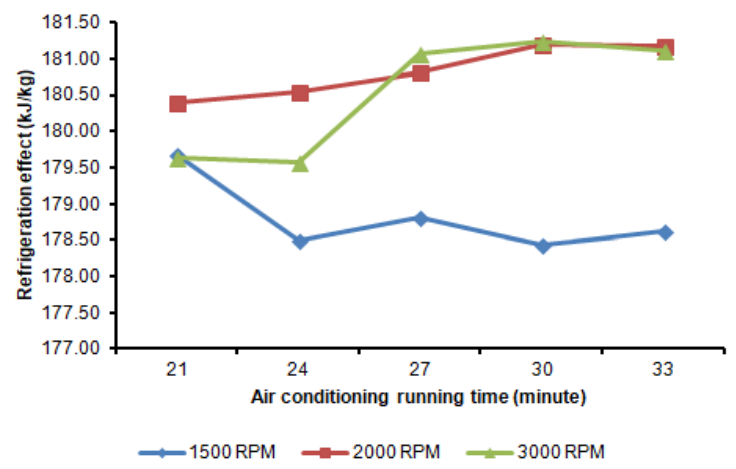

Fig. 3. Value of refrigeration effect based on time interval on testing using ejector.

Overall, the largest refrigeration effect was achieved in the $2000 \mathrm{rpm}$ test with a value of $181.18 \mathrm{~kJ} / \mathrm{kg}$. The value is slightly higher than the $3000 \mathrm{rpm}$ test condition with a value of $181.11 \mathrm{~kJ} / \mathrm{kg}$. At the beginning of the 
test, the value of the refrigeration effect at $2000 \mathrm{rpm}$ is higher than the other two rpm values of $180.40 \mathrm{~kJ} / \mathrm{kg}$. While the value of refrigeration effect at $1500 \mathrm{rpm}$ and $3000 \mathrm{rpm}$ respectively of $179.68 \mathrm{~kJ} / \mathrm{kg}$ and $179.64 \mathrm{~kJ} / \mathrm{kg}$. Furthermore, the value of the refrigeration effect at 2000 $\mathrm{rpm}$ and $3000 \mathrm{rpm}$ increased significantly. While the value of the effects of refrigeration at $1500 \mathrm{rpm}$ decreased dramatically.

Based on the results of two test conditions (normal and ejector use) on three rpm variations, there was an increase of refrigeration effect value of $21 \%-25 \%$ in AC system using ejector. This indicates that ejector installation on AC system can improve the refrigeration effect of normal AC system. The greater the value of the refrigeration effect then the amount of heat that can be absorbed by the refrigerant from the cabin space is greater [6].

\subsection{Coefficient of performance (COP)}

Figure 4 shows the COP value of the AC system under normal conditions testing. The test is done on three variations of rpm that is $1500 \mathrm{rpm}, 2000 \mathrm{rpm}$, and 3000 rpm. In general, COP achieved at $1500 \mathrm{rpm}$ is higher than in two other rpm conditions. At the beginning of the test, the COP achieved was 7.37. Then the value increased to 8.35 in the 24 th minute. After that, the value falls gradually to 7.81 at the end of the test. Although the COP value at $1500 \mathrm{rpm}$ decreased throughout the test, the value was still higher than the $2000 \mathrm{rpm}$ and 3000 rpm conditions, respectively of 7.13 and 7.36 .

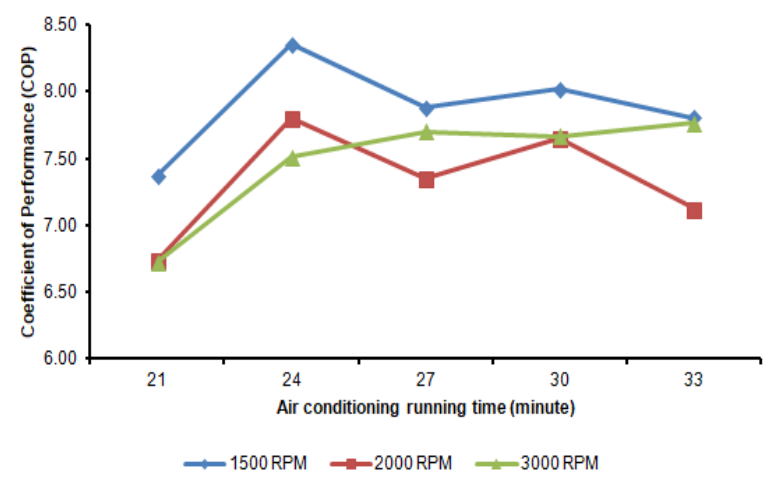

Fig. 4. COP value based on time interval on normal condition testing.

The test results using ejector are shown in Figure 5. Overall, the COP value at $1500 \mathrm{rpm}$ is higher than the $2000 \mathrm{rpm}$ and $3000 \mathrm{rpm}$ conditions. At the beginning of the test, the COP was 10.37. Although the value is smaller than the COP at $2000 \mathrm{rpm}$ of 11.46 , but in the 24th minute the COP at $1500 \mathrm{rpm}$ increased rapidly to 13.28. After that, the COP drops gradually until the end of the test is 9.55 . Test conditions at $2000 \mathrm{rpm}$ decreased COP from testing to the end of the test. At the end of the test obtained COP of 7.89. On the other hand, at 3000 rpm COP at the beginning of the test is 9.28. Then rise gradually until the end of the test obtained COP of 9.47. Although there is an increase in COP, but the value is still smaller than the condition at $1500 \mathrm{rpm}$.

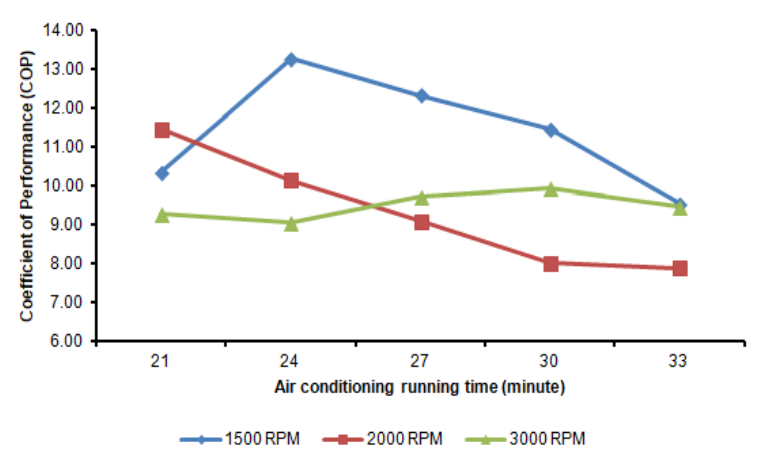

Fig. 5. COP value based on time interval on testing using ejector.

Based on the test results of two test conditions (normal and ejector use) on three rpm variations, there is an increase of COP in the AC system using ejector by $10 \%-22 \%$. This result is relevance with previous researchers who performed computational analysis [10]. The great value of COP indicates that the system worked properly. The value of COP is influenced by the amount of heat which can be absorbed by the refrigerant flowing in the evaporator (refrigeration effect), and the compression work performed by the compressor. If the value of the refrigeration effect is big and the value of compression work are small, the COP obtained will be large. The bigger the value of the refrigeration effect and the smaller the value of the compression work, the value of COP obtained will be better.

\section{Conclusions}

Research on the improvement of car air conditioning system performance using ejector has been done. To show improvement of AC system performance, the test is done on two different conditions (normal and use ejector). The results showed that ejector usage on AC system generates an increase in the refrigeration effect and coefficient of performance (COP) of $25 \%$ and $22 \%$, respectively. This has implications to better cooling capacity and compressor work that is lighter.

Acknowledgements: This work was financially supported by a Grant-in-Aid from the Directorate General of Research, Technology, and Higher Education of Indonesia, fund no: 30/EKPT/2017 (Skim Program Unggulan Perguruan Tinggi).

\section{References}

1. C.C. Shen, J.H. Lu, "Analysis of the performance of the evaporator of automotive air conditioning system,” Int. J. Automot. Technol. (2014)

2. M. Bentrcia, M. Alshatewi, H. Omar, "Developments of vapor-compression systems for vehicle air-conditioning: A review," Advances in Mechanical Engineering (2017) 
3. M.N.M. Lazin, I.Z.M. Darus, B.C. Ng, H.M. Kamar, "Identification for automotive air-conditioning system using Particle Swarm Optimization," in 2013 3rd Australian Control Conference, AUCC 2013 (2013)

4. H. Khayyam, A.Z. Kouzani, E.J. Hu, S. Nahavandi, "Coordinated energy management of vehicle air conditioning system," in Applied Thermal Engineering (2011)

5. M.A. Lambert, B.J. Jones, "Automotive adsorption air conditioner powered by exhaust heat. Part 1: Conceptual and embodiment design," Proc. Inst. Mech. Eng. Part D J. Automob. Eng. (2006)

6. E.T. Berman, A. Setiawan, E.S. Arifianto, Mutaufiq, "Evaluation of performance an air conditioning systems using t-junction flash gas refrigerant," in IOP Conference Series: Materials Science and Engineering, 288 (1), (2018)

7. P. Chaiwongsa, S. Wongwises, "Experimental study on R-134a refrigeration system using a two-phase ejector as an expansion device," Appl. Therm. Eng. (2008)

8. K. Sumeru, H. Nasution, F.N. Ani, "A review on two-phase ejector as an expansion device in vapor compression refrigeration cycle," Renewable and Sustainable Energy Reviews, 16 (7), 4927-4937 (2012)

9. A.A. Kornhauser, "The Use Of An Ejector as Refrigerant Expander," Int. J. Refrig. Air Cond. (1990)

10. N. Bilir, H.K. Ersoy, "Performance improvement of the vapour compression refrigeration cycle by a two-phase constant area ejector," Int. J. Energy Res. (2009)

11. K. Sumeru, S. Sulaimon, H. Nasution, F.N. Ani, "Numerical and experimental study of an ejector as an expansion device in split-type air conditioner for energy savings," Energy Build. (2014) 